\title{
Efficacy of dormancy breaking methods in paddy genotypes
}

\author{
D. Hanumanthappa ${ }^{* 1}$, S.N. Vasudevan ${ }^{2}$, K. Maruthi ${ }^{1}$, J.B. Maruthi ${ }^{1}$ and Anil Sebastian ${ }^{3}$ \\ ${ }^{1}$ Department of Seed Science and Technology, College of Agriculture, University of Agricultural Sciences Raichur \\ - 584 104, (Karnataka), INDIA \\ ${ }^{2}$ Department of Seed Science and Technology, College of Agriculture, University of Agricultural Sciences Raichur \\ - 584 104, (Karnataka), INDIA \\ ${ }^{3}$ Department of Seed Science and Technology ,Tamil Nadu Agricultural University, Coimbatore-641003 \\ (Tamil Nadu), INDIA \\ *Corresponding author. E-mail: dasah4508@gmail.com
}

Received: August 15, 2015; Revised received: January 13, 2016; Accepted: April 20, 2016

\begin{abstract}
Paddy plays a pivotal role in Indian agriculture. It also possesses dormancy which needs to be studied thoroughly. Duration of dormancy usually ranges from 7 to 35 days. Environmental conditions that facilitate after-ripening in paddy is generally cool, moist substrate conditions referred to as stratification, chilling, or moist chilling, oxygen and other gases. 12 paddy genotypes were selected for the present investigation with various physical and chemical dormancy, breaking methods for freshly harvested seeds and the standard germination test was conducted thereafter. At $1 \%$ level of significance, heat treatment at $45^{\circ} \mathrm{C}$ for $72 \mathrm{~h}$ showed significantly highest mean germination (82.86\%), seedling vigour index (2753), dehydrogenase activity (0.0449) and alpha amylase activity $(12.14 \mathrm{~mm})$ compared to other treatments and control.. The vigour index increased to $2753\left(\mathrm{GA}_{3} @ 50 \mathrm{ppm}\right)$ from 985 in control. Significantly higher EC leachates was recorded in control (0.602) and lowest in heat treatment at $45{ }^{\circ} \mathrm{C}$ for $72 \mathrm{hr}(0.182)$ followed by $\mathrm{HNO}_{3} @ 1.5 \%(0.202)$ and $\mathrm{GA}_{3} @ 50$ ppm $(0.250)$ irrespective of the genotypes at 1\% level of significance. Pre-heat treatment was followed by, $\mathrm{HNO}_{3} @ 1.5 \%$ and $\mathrm{GA}_{3} @ 50$ ppm for germination $(80.75 \%, 77.72 \%)$, dehydrogenase activity $(0.0446,0.0443)$ and alpha amylase activity $(12.10 \mathrm{~cm}, 11.60$ $\mathrm{cm}$ ) respectively. The study is an exploration of cost effective treatment to alleviate seed dormancy in paddy with the background of biochemical observations for scientific explanation.
\end{abstract}

Keywords: Dormancy, Ethrel,Germination, Heat treatment, Paddy

\section{INTRODUCTION}

Paddy is the world's most important food crop and a primary food source for more than one third of world's population (Singh and Singh, 2008). Paddy occupies a pivotal role in Indian agriculture. It is the staple food for more than 70 per cent Indians and a source of livelihood for 120-150 million rural households. The total area under rice cultivation in India accounts to 43.95 million hectares with a production of 106.54 million tonnes and productivity of 2424 kilograms per hectare (DAC, 2014). It provides more than fifty per cent of daily calorie intake and considered as the cheapest source of food, energy and protein in the developing countries. It contributes about 43 per cent of total food grain production and 53 per cent of cereal production, thus continues to hold the key to sustain food sufficiency in the country. Presence of seed dormancy in paddy is both problematic as well as advantageous. It is problematic for postharvest seed testing and it is advantageous in avoiding viviparous germination in tropical cultivars grown during monsoon season. The premature germination of seeds within ears/pods (vivipary) occurs when the crops are exposed to a wet weather favourable for germination just before harvest (Elizabeth Farnsworth, 2000). In such cases, a preharvest rain leads to deterioration in the quality of crop produce, it reduces seed quality and vigor, milling and backing quality and even grain.

There is a need for its safe removal, if the seeds are to be planted immediately after harvest. Various methods are being employed in many crops for breaking seed dormancy such as scarification, stratification (chilling), chemical treatment, leaching, priming etc., depending on the nature of dormancy (Liela et al., 2005; Lam and Edralina, 2011). Knowledge on the various seed dormancy breaking methods is very much useful to the farmer who takes up seed production or crop production immediately after harvest. Keeping in view of the above aspects, the present investigation was taken up with 12 paddy genotypes to overcome the seed dormancy in paddy genotypes by various dormancy breaking methods. Through this study, a cost effective dormancy breaking treatment can be provided to the farming community so as to avoid delay in sowing. Dormancy breaking treatments are required for faster breeder seed production as well. 


\section{MATERIALS AND METHODS}

The seed material used to study the efficacy of seed dormancy breaking treatments consisted of 12 paddy genotypes with different duration of maturity and was obtained from Agricultural Research Station, Gangavathi, University of Agricultural Sciences, Raichur. The laboratory experiment was carried out during the year 2013-14 with three replications with two factorial completely randomized design (CRD). Various physical and chemical dormancy breaking treatments viz., control, exposure to $45^{\circ} \mathrm{C}$ for $24 \mathrm{hr}$, exposure to $45^{\circ} \mathrm{C}$ for $48 \mathrm{hr}$, exposure to $45^{\circ} \mathrm{C}$ for $72 \mathrm{hr}$, Soaking in $\mathrm{GA}_{3}$ at $25 \mathrm{ppm}$, Soaking in $\mathrm{GA}_{3}$ at $50 \mathrm{ppm}$, Soaking in $\mathrm{KNO}_{3}$ at 0.5 per cent, Soaking in $\mathrm{KNO}_{3}$ at 1 per cent, Soaking in $\mathrm{HNO}_{3}$ at 1 per cent, Soaking in $\mathrm{HNO}_{3}$ at 1.5 per cent, Soaking in ethrel at $50 \mathrm{ppm}$, Soaking in ethrel at $100 \mathrm{ppm}$, exposure to sun light for $48 \mathrm{hr}$ and water soaking for $24 \mathrm{hr}$ were imposed to break the dormancy of freshly harvested seeds. For the chemical treatments, soaking duration was $24 \mathrm{hr}$ and the standard germination test was conducted thereafter.

The treated paddy seeds were surface dried and tested for germination. Between paper methods of germination test as prescribed by the International Seed Testing Association (2013) was followed. Four replication of 100 seeds each were randomly counted and placed on the germination paper at uniform spacing of $25 \mathrm{~mm}$ between seeds in row. The rolled paper towels with seeds were secured at both the ends with rubber bands and placed vertically in cabinet of seed germinator by maintaining a constant temperature of $25 \pm 1{ }^{\circ} \mathrm{C}$ and relative humidity of $90 \%$. The germination was recorded on $14^{\text {th }}$ day and based on normal seedlings produced. The germination was recorded on $14^{\text {th }}$ day and based on normal seedlings produced; the germination percentage was worked out. The seedling vigor index was determined by multiplying the percentage germination and total seedling length (Abdul-Baki and Anderson, 1973). Dehydrogenase activity was reported as the optical density (OD) value obtained as suggested by Shenoy et al. (1990). Representative seeds (25) from each treatment were taken and preconditioned by soaking in water for overnight at room temperature. Seeds were taken at random and the embryos were excised. The embryos were steeped in 0.25 per cent solution of 2, 3, 5-triphenyl tetrazolium chloride solution and kept in dark for two hours at $40{ }^{\circ} \mathrm{C}$ for staining. The stained seeds were thoroughly washed with water and then soaked in five $\mathrm{ml}$ of 2 methoxy ethanol (methyl cellosolve) and kept overnight for extracting the red colour formazan. The intensity of red colour was measured using ELICO UV-VI Spectrophotometer (model SL-159) using blue filter (470 $\mathrm{nm})$ and methyl cellosolve as the blank. The OD value obtained was reported as dehydrogenase activity. The $\alpha$-amylase activity was analyzed as per the method suggested by Simpson and Naylar (1962) with slight modifications. The mean values of the data were statistically analyzed

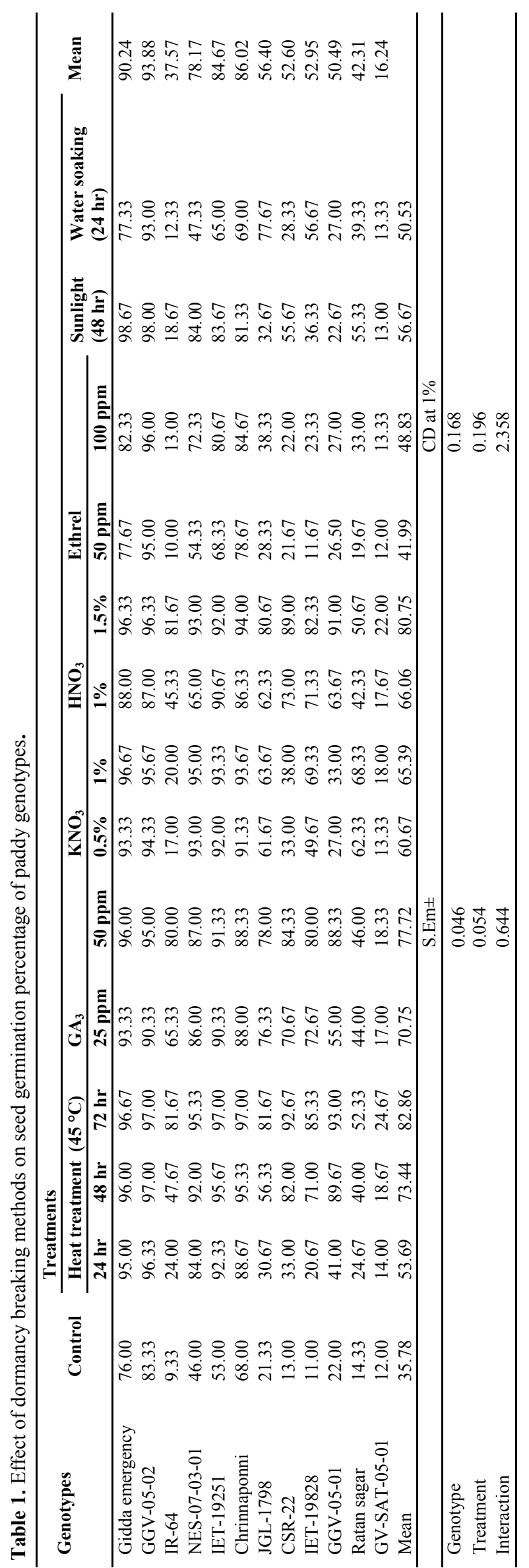



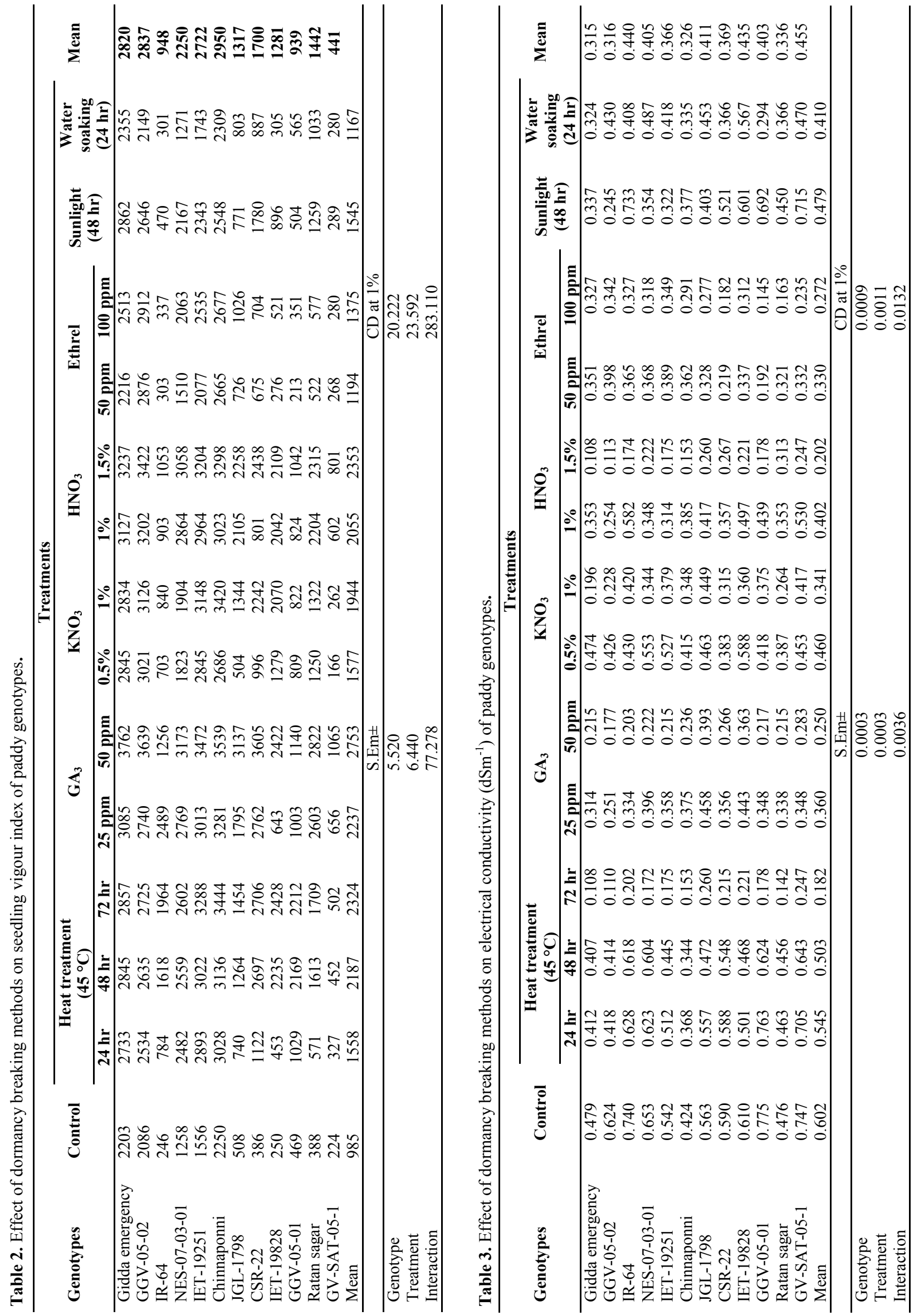

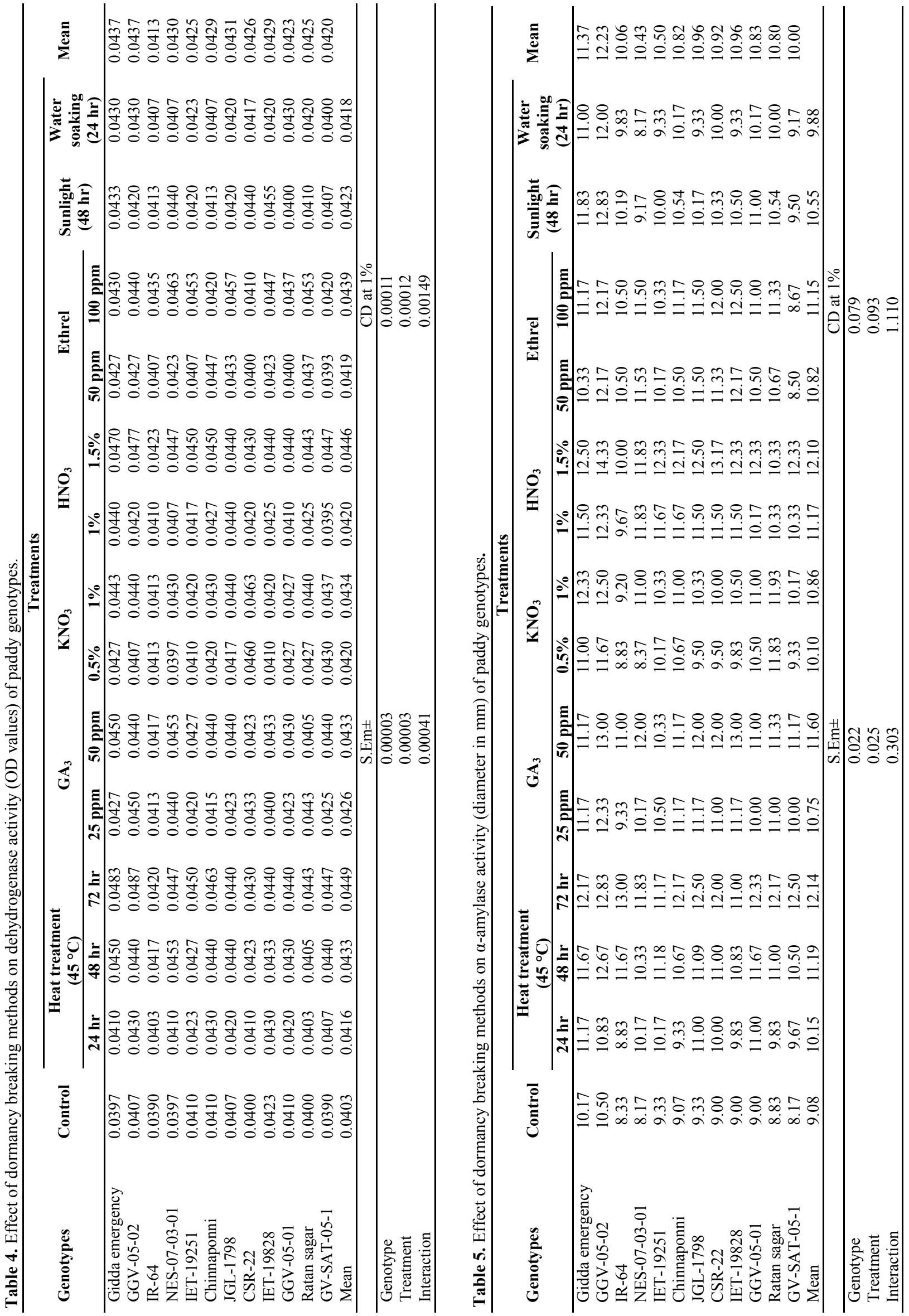
following completely randomized factorial design (CRFD) for laboratory studies; significance was tested by referring to ' $F$ ' table of Fisher and Yates (1963).

\section{RESULTS AND DISCUSSION}

The various dormancy breaking pre-treatments had different effect on germination in different paddy genotypes. Untreated paddy seeds generally showed low germination indicating initial poor germination, which showed that pre-treatments are required to overcome the dormancy so as to improve the germination. The pre-heat treatment at $45{ }^{\circ} \mathrm{C}$ for $72 \mathrm{hr}$ recorded maximum mean germination $(82.86 \%)$ followed by $\mathrm{HNO}_{3} @ 1.5 \%(80.75 \%)$ and $\mathrm{GA}_{3} @ 50$ ppm (77.72\%) and minimum in control (35.78\%) (Table 1). This increased germination due to heat treatment possibly helped in overcoming the restriction of availability of oxygen to the embryo by increasing cracks in the hulls or reducing the peroxidise activity in the seed covering structures thereby promoting the degradation and evaporation of short chain saturated fatty acids (SCSFAs) from the dormant seeds thereby increasing the germinability. This confirms the earlier findings of Kota et al. (2006), who suggested dry heat treatment and Abdul et al. (2012), who observed increase in germination of hulled rice seeds after heat treatment at 50 ${ }^{\circ} \mathrm{C}$ in rice cultivars.

Estimation of seedling vigour indices is an important seed quality parameter as reported by Abdul Baki (1980) in soybean In the present study, the seedling vigour as reflected through seedling length and dry matter also increased due to $\mathrm{GA}_{3}$ over the other chemical treatments. The vigour index increased to 2753 $\left(\mathrm{GA}_{3} @ 50 \mathrm{ppm}\right)$ from 985 in control (Table 2.). Asborno et al. (1999) reported that $\mathrm{GA}_{3}$ increased the coleoptiles elongation and field emergence whereas, Taegsu and byunwoo (2000) found mesocotyl elongation with the application of $\mathrm{GA}_{3} @ 500$ ppm in paddy. Omkar singh and Kumar (1999) observed that $\mathrm{GA}_{3}$ increased germination, speed of germination and field emergence index in pigeon pea. Higher seedling vigour index might be due to exogenous application of $\mathrm{GA}_{3}$ which leads to activation of various enzymes responsible for conversion of complex food material into simpler form, which ultimately facilitates more availability of food reserves to the growing embryo thereby, increases the seedling vigour as observed by Ankaiah et al., 1993 in sunflower and Gowda, 2003 in paddy during $\mathrm{GA}_{3}$ exogenous application.

At $1 \%$ level of significance, higher EC leachates was recorded in control (0.602) and lowest in heat treatment at $45{ }^{\circ} \mathrm{C}$ for $72 \mathrm{hr}(0.182)$ followed by $\mathrm{HNO}_{3}$ @ 1.5\%(0.202) and $\mathrm{GA}_{3} @ 50$ ppm (0.250) irrespective of the genotypes at $1 \%$ level of significance.(Table 3 ). Similar results were also reported by Liela et al. (2005) in paddy for thermal hardening treatment.

Similarly, dehydrogenase activity was also enhanced in all the dormancy breaking methods irrespective of the genotypes. But its activity was highest in the seeds exposed to heat treatment at $45{ }^{\circ} \mathrm{C}$ for $72 \mathrm{hr}(0.0449)$ followed by $\mathrm{HNO}_{3} @ 1.5 \%(0.0446)$ and $\mathrm{GA}_{3} @ 50$ ppm (0.0443) compared to control (0.0403) (Table 4.). The results suggest that the dehydrogenase enzyme activity is an important indicator of breaking dormancy in paddy seeds and also an efficient indicator of the degree of dormancy in the paddy seeds. (Antonio et al., 2002). It is postulated that release from dormancy is associated with an increased activity of pentose phosphate pathway (PPP) dehydrogenases (Hendricks and Taylorson, 1974) as catalases and PPP activity is more during germination due to increased respiration, hydrolysis of stored food materials and energy synthesis. The present study also confirms that dehydrogenase activity is increased in all the dormancy breaking treatments. However, Stephen and Ross (1981) in oats reported that there is no obvious connection between dormancy breakage and increased activity of pentose phosphate pathway dehydrogenases. But, the present study is contradictory to this finding.

Significantly higher alpha amylase activity at $1 \%$ level of significance was recorded in heat treatment at $45^{\circ} \mathrm{C}$ for $72 \mathrm{hr}$ (12.14) followed by $\mathrm{HNO}_{3} @$ 1.5\% (12.10) and $\mathrm{GA}_{3} @ 50$ ppm (11.60) and least in control (9.08) irrespective of the genotypes (Table 5). The present result are in conformity with Lam et al. (2011), who reported that, heat treatment method of breaking paddy seed dormancy is only effectively enhanced germination rate together with enhanced respiration rate, ethylene production and $\alpha$-amylase activity. Dormant cultivars had higher $\mathrm{O}_{2}$ uptake rate and peroxidase activity and lower amylase and dehydrogenase activities than the weakly dormant ones. Seshu and Dadlani (1991) and Garzia-Maya et al. (1990) reported that abscisic acid (ABA) inhibit the gibberellic acid induction of $\alpha$ amylase synthesis and consequently, prevent seeds from initiating germination.

\section{Conclusion}

Among the dormancy breaking treatments, heat treatment at $45^{\circ} \mathrm{C}$ for $72 \mathrm{~h}$ showed significantly highest mean germination, seedling vigour index, dehydrogenase activity and alpha amylase activity compared to other treatments and control at $1 \%$ level of significance and hence considered as the best dormancy alleviation treatment for dormancy in paddy. The outcome of the experiment will help in breaking the seed dormancy of various paddy genotypes, so that the crop scientists and seed producing organisations can take up the seed production of various classes viz., nucleus seed, breeder seed, foundation seed, certified seed and truthfully labelled seed immediately after harvest in order to meet the required quantity of high quality seeds of improved genotypes and also it facilitates the paddy farmers to raise the second crop. The study is a new exploration towards revealing the cost effective treatment for dormancy breaking in paddy confirmed 
through biochemical and physiological parameter analysis of the resultant seeds.

\section{REFERENCES}

Abdul Waheed, Habib Ahmad and Fida Abbasi, M. (2012). Different treatment of rice seed dormancy breaking, germination of both wild species and cultivated varieties. Journal of Meteorological Environmental Science. 3: 551-560.

Abdul-Baki, A.A. and Anderson, J.D. (1973). Vigour determination in soybean seed by multiple criteria. Crop Science. 1: 630-633.

Abdul-Baki, A.A. (1980). Biochemical aspects of seed vigor. Horticulture Science. 15: 761-765.

Ankaiah, R., Reddy, B.M., Roa, D.V.S.R. and Saibabu, K.G. R.S. (1993). Studied on seed dormancy in sunflower (Helianthus annus). Journal Research APAU. 21 (3): 142-146.

Antonio, R.V., Maria Das, Antonio, C.F., Joao, A.O. and Custodio, D.D. (2002). Action of gibberellic acid $\left(\mathrm{GA}_{3}\right)$ on dormancy and activity of $\alpha$-amylase in rice seeds. Revista Brasileira de Sementes. 24: 43-48.

Asborno, M.D. Vidal, A.A., Benzusr and Beltrano, J. (1999). Rice: temperature and gibberllic acid effect on initial growth stages. Agro. Ciencia. 15 (1): 47-53.

Department of Agriculture cooperation and farmers welfare. (2014). www. Agricoop.nic.in.

Elizabeth Farnsworth. (2000). The ecology and physiology of viviparous and recalcitrant seeds. Annual Review of Ecology and Systematics. 31: 107-138.

Fisher, R.A. and Yates, F. (1963). Statistical tables for biological, agricultural and medical research. Oliver and Boyd, London. 145.

Garzia-Maya, M., Chapman, J.M. and Black, M. (1990). Regulation of $\alpha$ - amylase formation and gene expression in developing wheat embryo. Planta. 181: 296-303.

Gowda, R., Swaranna, C., Devaraju, P.J. and Chandra, B.V. (2003). Dissipation of dormancy and its breaking methods in KRH-2 Hybrid rice and its parental lines. Seed
Res. 31 (1): 102-104.

Hendricks, S.B. and Taylorson, R.B. (1974). Promotion of seed germination by nitrate, nitrite, hydroxylamine, and ammonium salts. Plant physiol. 54: 304-309.

International Seed Testing Association. (2013). International rules for seed testing. Seed Sci. and Technol. 29 (supplement): 1-135.

Kota Janaiah, Kant, K. and Dadlani, M. (2006). Efficacy of dormancy breaking methods in indica rice varieties. Seed Res. J. 34: 45-49.

Lam Dong Tung and Edralina Serrano. (2011). Effects of warm water in breaking dormancy of rice seed. Omonrice, 18: 129-136.

Liela,Y., Abbas, Z., Saman, S. and Fardin, K. (2005). Influence of High and Low Temperature Treatments on Seed Germination and Seedling Vigour of Rice (Oryza sativa L.). World Applied Sci. J. 16 (7): 1015-1018.

Omkar Singh, D. and Kumar, A. (1999). The effect of plant growth regulator on seed quality in partially aged seeds of pigeon pea. Seed Res. 27 (1): 54-59.

Seshu, D.V. and Dadlani, M. (1991). Mechanism of seed dormancy in rice. Seed Sci. and Technol. 1: 187-194.

Shenoy, V.V., Seshu, D.V. and Dadlani, M. (1990). Association of laboratory assessed parameter with field emergence in rice. The non-anoic acid stress as a seed vigour test. Seed Res. 18 (1): 60-69.

Simpson, G.M. and Naylar, J.M. (1962). Dormancy studies in seeds of Avena fatuva and a relationship between maltase, amylases and gibberellins. Can. J. Bot. 40: 1959-1673.

Singh,Y. and Singh, U.S. (2008). Genetic diversity analysis in aromatic rice germplasm using agro- morphological traits. J. Plant Genet. Resour. 21 (1): 32-37.

Stephen Adkins and James Ross. (1981). Studies in wild oat seed dormancy. Plant Physiol. 67: 358-362.

Taegsu, N. and Byunwoo, L. (2000). Effect of seed soaked in $\mathrm{GA}_{3}$ and inorganic salt on mesocotyl and coleoptile elongation in rice, Korean J. Crop Sci. 45 (1): $52-54$. 